\title{
Facing the Harsh Reality of Access and Benefit Sharing (ABS) Legislation: An Industry Perspective
}

\author{
Frank Michiels ${ }^{1}$, Ulrich Feiter ${ }^{2}$, Stéphanie Paquin-Jaloux ${ }^{3}$, Diana Jungmann ${ }^{4}$, Axel Braun ${ }^{5}$, Mary Ann P. Sayoc ${ }^{6}$, \\ Ricard Armengol ${ }^{7}$, Markus Wyss ${ }^{8, *(\mathbb{D})}$ and Bruno David ${ }^{9}$ \\ BASF Belgium Coord. Center CommV, Innovation Center Gent, 9052 Gent, Belgium; frank.michiels@basf.com \\ 2 Parceval Pty, Wellington 7655, South Africa; ulrich.feiter@parceval.co.za \\ Firmenich SA, 1242 Satigny, Switzerland; stephanie.paquin.jaloux@firmenich.com \\ 14Bisness Consulting Ltda., Brasilia 70756-530, Brazil; diana@14bisness.com \\ F. Hoffmann-La Roche AG, 4070 Basel, Switzerland; axellbraun@outlook.com \\ East-West Seed Company, Inc., Bulacan 3008, Philippines; maryann.sayoc@eastwestseed.com \\ Provital SAU, 08210 Barberà del Vallès, Spain; r.armengol@weareprovital.com \\ DSM Nutritional Products Ltd., CH-4303 Kaiseraugst, Switzerland \\ 9 Pierre Fabre Research Institute, Green Mission, 31035 Toulouse, France; brunoxdavid@gmail.com \\ * Correspondence: markus.wyss@dsm.com
}

check for

updates

Citation: Michiels, F.; Feiter, U.;

Paquin-Jaloux, S.; Jungmann, D.; Braun, A.; Sayoc, M.A.P.; Armengol, R.; Wyss, M.; David, B. Facing the Harsh Reality of Access and Benefit Sharing (ABS) Legislation: An Industry Perspective. Sustainability 2022, 14, 277. https://doi.org/ $10.3390 /$ su14010277

Academic Editor: Antonio Boggia

Received: 21 November 2021

Accepted: 22 December 2021

Published: 28 December 2021

Publisher's Note: MDPI stays neutral with regard to jurisdictional claims in published maps and institutional affiliations.

Copyright: (C) 2021 by the authors. Licensee MDPI, Basel, Switzerland. This article is an open access article distributed under the terms and conditions of the Creative Commons Attribution (CC BY) license (https:// creativecommons.org/licenses/by/ $4.0 /)$.

Abstract: Access and benefit sharing (ABS) is a framework which refers to a relatively recent type of legal requirements for access to and use of "genetic resources". They are based on diverse national and regional laws and regulations, which mostly result from the implementation of the United Nations' Convention on Biological Diversity (CBD) and its supplementary agreement, the Nagoya Protocol. Their ambition is to achieve fair and equitable sharing of benefits arising out of the use of genetic resources as an incentive to conserve and sustainably use them. This paper describes the experiences, practical constraints and complexities encountered by users of genetic resources when dealing with ABS legislation, with a focus on users from the private sector. We provide insights on how ABS laws have fundamentally changed the way of working with genetic resources, in the hope that it inspires re-thinking of the ABS framework, to better support the overall objectives of the CBD.

Keywords: convention on biological diversity; access and benefit sharing; Nagoya protocol; industry perspective

\section{Introduction}

The United Nations' Convention on Biological Diversity (CBD), concluded at the Rio de Janeiro Earth Summit in 1992, has three main objectives, namely the conservation of biological diversity, the sustainable use of its components, and the fair and equitable sharing of benefits arising from the utilization of genetic resources [1]. In 2010, the Nagoya Protocol was adopted as a supplementary agreement to the CBD, specifically addressing the third objective of the CBD [2]. The stated objective of the Nagoya Protocol (Art. 1) is "the fair and equitable sharing of benefits arising from the utilization of genetic resources, including by appropriate access to genetic resources and by appropriate transfer of relevant technologies, taking into account all rights over those resources and to technologies, and by appropriate funding, thereby contributing to the conservation of biological diversity and the sustainable use of its components". The Nagoya Protocol entered into force in 2014.

An important pillar of the CBD and the Nagoya Protocol is the recognition of sovereign rights of states over their natural resources, and that the authority to determine access to genetic resources rests with national governments and is subject to national legislation (CBD Art. 15). This principle of national sovereignty was thought to enable and facilitate other obligations of contracting parties to the CBD, such as conservation and sustainable use of biodiversity, in situ and ex situ conservation, as well as technical and scientific 
cooperation. Applied specifically to the Nagoya Protocol, this means that every ratifying party is entitled to establish its own access and benefit sharing (ABS) legislation, as long as it respects the minimum standards and basic principles enshrined in the CBD and the Nagoya Protocol. The Nagoya Protocol sets out a framework, wherein each country has substantial freedom, and can choose, as extremes, (i) either not to regulate access to its genetic resources altogether, or (ii) to impose ABS obligations that are, in effect, so onerous that they discourage rather than facilitate access to biodiversity. Some countries have even created new terms and requirements that are broader in scope than stipulated by the CBD and the Nagoya Protocol.

The private sector has expressed support for the overall objectives of the CBD and the Nagoya Protocol (e.g., [3]). This is part of a commitment to fair and ethical business practices and sustainability in all its dimensions (i.e., social, environmental, and economic), often subsumed under the term "Corporate Social Responsibility", and it supports business continuity with clients, customers, suppliers, regulators, authorities, and investors.

The business community also strives to comply with the detailed requirements of all national and regional ABS laws. It was hoped that the Nagoya Protocol would provide a mechanism for ABS that is workable, transparent, and satisfactory for all stakeholders, and that supports the overall objectives of the CBD. However, more than 10 years after the conclusion of the Nagoya Protocol, access to genetic resources and ABS regulations in general continue to present many challenges for the private sector, as is also reflected in a recent user survey in the EU [4]. A selection of these challenges is outlined in detail in this paper.

In the end, a political instrument will be most efficient and successful if all stakeholders fully support not only the ambitions, but also the translation of these ambitions into the practical realities of everyday life. Therefore, we hope that this paper helps everyone involved in the international debate on ABS, be it providers of biodiversity (e.g., national competent authorities and indigenous peoples and local communities) or other users (e.g., from academia), be it policy makers or practitioners, to better understand the priorities and constraints of the private sector, and that it thereby eases discussions about a better approach to ABS.

\section{Framework Requirements for Industrial Innovation}

The planet faces formidable challenges, notably in terms of climate change, biodiversity loss, and land degradation. Food security, public and animal health, and growth in wealth and prosperity should be enabled across the globe while drastically reducing our environmental footprint. This is described in the First Draft for the Post-2020 Global Biodiversity Framework [5]. Multiple solutions and policy elements may need to be implemented to address these challenges, and proposals have been put forward, a.o., for a circular (bio-) economy, or for nature-based solutions. It has been proposed to eliminate or redirect harmful subsidies and to create biodiversity offsets to accelerate the transition, and as a means of resource mobilization [6]. Each of these solutions will require innovation, and in many cases will involve use of genetic resources. Innovation is key to finding efficient solutions for a more sustainable future. It is the cornerstone of sustained economic growth and prosperity.

Innovation (involving genetic resources or not) is often a long journey. In the private sector, it requires the foresight of investors who are prepared to spend the work and pay the development costs (often over multiple years). At an early stage of the development journey, it is common practice for investors to perform a return-on-investment (ROI) calculation (also known as a business case), as a basis for investment decisions, and to identify the most relevant opportunities. The better the projection of costs and revenues and value creation over time, the higher the quality and credibility of a business case.

Not knowing at the outset of a project whether a provider country of a genetic resource will at all grant a permit for commercialization under its ABS laws, or ambiguous monetary benefit sharing obligations, or a risk of retro-active application of any legal provisions 
compromises the quality of the ROI calculation, increases the risk for private sector investors, and may thereby derail investment decisions for biodiversity-based innovations and, accordingly, the potential for any form of benefit sharing is lost.

\section{Reality Check: Challenges Encountered in the Daily Practice of ABS}

In the following subsections, a series of reflections and experiences will be outlined that hope to shed light on the apparent discrepancy between the honourable ambitions of the CBD and the Nagoya Protocol on the one hand, and the shortcomings of the current implementation of ABS on the other hand. We will start with a view on expectation management. Next, we will emphasize the importance of legal certainty for the private sector, and why it is compromised due to ambiguities in the material or temporal scope of obligations, or to challenges in dealing with traditional knowledge. Finally, we will explain the additional layers of complexity that are intrinsic to typical value and supply chains in a globalized economy.

\subsection{Expectation Management}

Successful innovation is a rare and largely unpredictable endeavour. There is a saying that in $R \& D$, only one out of ten experiments is successful in advancing our knowledge. With even much lower probability, a discovery can be turned into a useful product that may or may not be commercially viable; finding, developing, and leveraging a commercial blockbuster product is an extremely rare event. As an illustration, Pierre Fabre, a French pharmaceutical and dermo-cosmetics group, conducted an extensive plant extract screening program between 1998 and 2015, employing a dedicated group of roughly 30 people. The objective was to isolate drug candidate molecules via high-throughput screening campaigns on a large number of plant extracts. The collection of dry plant parts was probably the largest private collection in the world with over 17,000 plant samples. This unique collection has even become a "registered collection" in connection with the EU ABS Regulation No $511 / 2014$, which attested to the legality of access and management. In spite of the immense efforts undertaken, not a single molecule entered clinical development. In the end, the endeavour was stopped, and the entire team was disbanded.

This example and similar experiences previously at Merck, Pfizer, Sanofi, or GSK [7] underline the fundamental challenge of the low probability of success of natural productsbased drug discovery programs. If the ambition is to secure that every single use of every genetic resource that is accessed is subject to bilateral benefit sharing agreements, this will inevitably result in demanding ABS procedures requiring extensive tracking and tracing. The associated costs and bureaucratic burden will obstruct rather than facilitate $R \& D$ (including research into the conservation of biodiversity), and will disincentivize the highthroughput natural product screening programs, which often are the first step for a new "utilization" of a genetic resource, both in the pharmaceutical industry as outlined above as well as in other industries. It may thus be worthwhile considering ABS mechanisms that may better support the ambitions of the CBD to facilitate access to biodiversity and its sustainable use in a win-win-win approach (for biodiversity, providers, and users, respectively). With obstacles to access, products will not be developed for which benefits can be shared.

\subsection{Complexity of ABS Legislation}

A first challenge to be discussed is the sheer complexity of ABS legislation. In a globalized economy, where companies typically source inputs from multiple countries and sell their products again in different markets, companies normally need to comply with a myriad of laws and regulations (e.g., trade, import, and export laws; tax and financial disclosure laws; and product approval or safety laws, etc.). Processes are easier for laws and regulations which have evolved over a long period of time, where there is a long history of sharing of best practices, and-above all—where there is a significant level of 
global harmonization and where the laws are sufficiently concrete and precise to offer legal certainty.

The reality for the Nagoya Protocol and ABS is very different: the Nagoya Protocol entered into force only in 2014, many countries have not yet (fully) established their ABS frameworks, have limited experience, or a combination thereof, and there is pronounced legal uncertainty due to, a.o., vague definitions. In addition, due to national sovereignty and each country being free to establish its own, particular, ABS set-up, there is a large variety across the globe in the scope of ABS laws as well as in the procedures to secure ABS compliance. Figure 1 gives an impression of the evolution of ABS laws and associated guidance documents over time, as published on the ABS Clearing House maintained by the CBD Secretariat. Users must comply with the laws, and with relevant parts of policies, strategies, explanations, and with requirements that are not (yet) published on the ABS Clearing House. When accessed on 14 October 2021, the ABS Clearing House had legally binding ABS documents from 60 countries, plus the European Union. Still, the coverage is incomplete: several countries that have laws relating to ABS have not uploaded them on the ABS Clearing House, e.g., Australia and New Zealand (see [8]), but also several others. There is a continuous appearance of a significant number of new laws, which may all need to be assessed for the potential relevance for a given company or user. Given the intrinsic complexities and ambiguities in ABS legislation, remaining informed of all new ABS laws is a significant challenge, even for large companies, but is a daunting if not prohibitive endeavour for small to medium-sized enterprises (SMEs). A recent survey [4] has confirmed that users experience ABS laws as burdensome, and sometimes simply not operational.

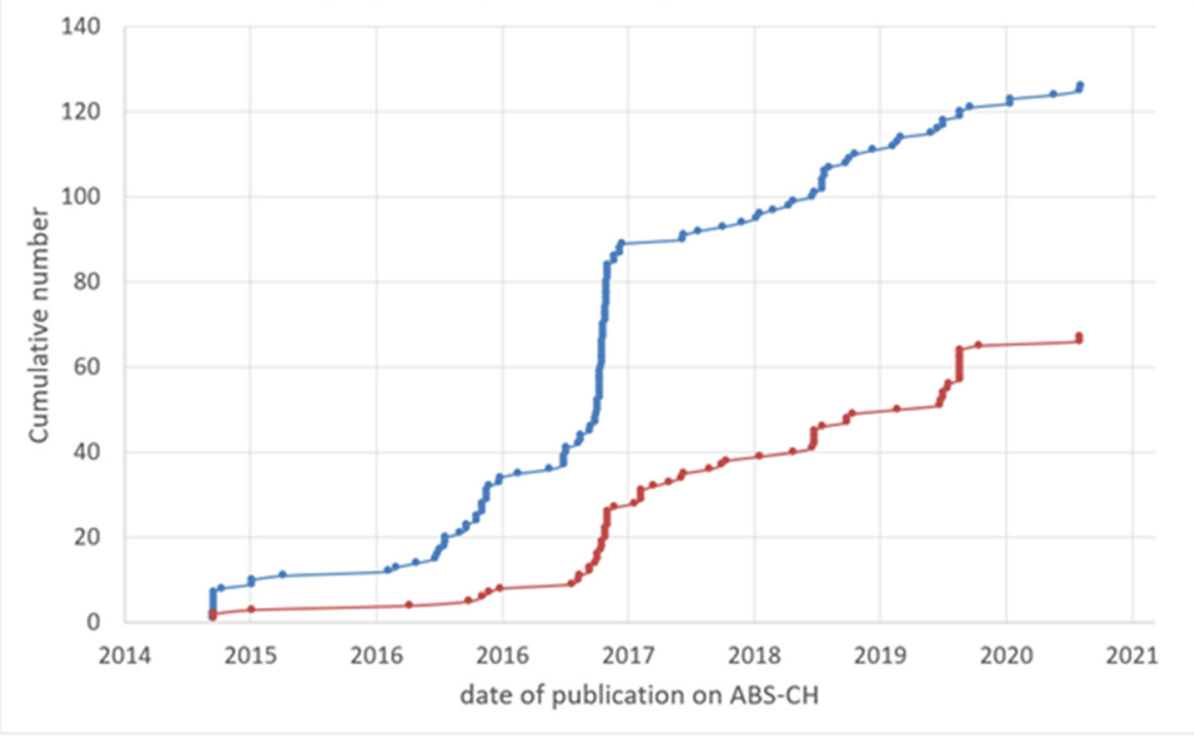

Figure 1. The numbers of laws (in blue) and of administrative or policy measures (in orange) are plotted as a function of time, based on information downloaded from the ABS Clearing House (https://absch.cbd.int) (accessed on 14 October 2021). Draft documents, duplicate entries, and non-legally binding documents are not included in the graph.

Considering that a multitude of different legal ABS requirements need to be followed in all countries in which a company is active, it would seem crucial that the laws are transparent and have a clearly defined scope and obligations. More particularly in the context of the Nagoya Protocol, users cannot afford to be left with unclear definitions and unresolved questions in terms of material and temporal scope of a law (see below), because this creates a high risk of litigation in combination with compromised reputation in the market. Accordingly, legal certainty is of utmost importance for the private sector. 
Regional or even global harmonization might offer significant relief. The European Union's ABS Regulation No 511/2014 may be regarded as a step in that direction, as it defines the compliance measures that need to be taken by all 27 member states to secure ABS compliance across the EU. However, the EU ABS Regulation only covers the compliance obligations, whereas for ABS, the principle of national sovereignty still applies, and each EU member state is free to establish its own ABS legislation (sometimes even at subnational level), as has occurred for example by France, Belgium, or Spain, where some regions (e.g., overseas territories) have developed their own regulations. Because companies strive for compliance with all applicable legislation, the harmonization offered by the EU ABS Regulation is, thus, of limited value; harmonization of ABS requirements and procedures would offer much more value to the industry or users of biodiversity in general.

\subsection{Intricacies of Compliance in Selected Provider Countries}

There are numerous challenges encountered by the industry when engaging with regulators and traditional knowledge (TK) holders in provider countries. Here, we will select insightful examples of types of problems, but will not attempt to exhaustively explain how widespread these problems are, and in which other countries they exist.

One important point of complexity is the extreme heterogeneity of national legislation. For instance, in some countries, such as Australia, different rules will apply depending on whether the resource comes from private or public lands, federal, state, or Commonwealth territories [8]. Another example of complexity in following the national regulations is in India, where the Biological Diversity Act 2002 prescribes different rules for Indian and non-Indian companies and citizens, and where-so far-approx. 270,000 local Biodiversity Management Committees (BMCs) have been established. India's National Biodiversity Authority as well as the State Biodiversity Boards are mandated to consult the BMCs while taking any decision relating to the use of biological resources and associated knowledge occurring within the respective territorial jurisdiction of the BMCs. Through this consultation process, participation or approval and involvement of the conservers and holders of the biological resources and associated TK in the determination of the conditions for ABS are ensured [9]. Commercialised biological resources and their derivatives are required to be accessed by non-Indian companies or citizens via a permit and benefit sharing agreement issued by the National Biodiversity Authority, despite the absence of "utilisation" as per the Nagoya Protocol definition. Although India defined certain exemptions, their interpretation varies from experts to national competent authorities and users. Therefore, implementation of India's ABS legislation is fastidious as foreign companies need to "negotiate" with national authorities on contractual clauses that are sometimes hard to accept.

In Brazil, micro and small enterprises represent $99 \%$ of Brazilian businesses and contribute $30 \%$ to the GDP [10]. Due to the broad definition of the term "technological development" in Brazil's ABS law 13,123/2015 [11], many of these businesses access Brazilian biodiversity. Currently, the Brazilian ABS legislation comprises one federal law, two regulatory decrees (with the first one having 120 articles) and over 30 infralegal rules (i.e., 23 resolutions and 10 technical guidance documents issued so far by the Genetic Heritage Council, CGen, of the Ministry of Environment) that need to be known, understood, and applied by ABS users. Although micro and small businesses are exempt from benefit sharing obligations, they still need to comply with registration obligations (i) for access to genetic heritage and associated TK, (ii) for transferring genetic heritage abroad, and (iii) prior to intellectual property right filings. In addition, they need to file pre-commercialization notifications, and obtain prior informed consent (PIC) for identifiable access to associated TK. Different from medium- and large-sized companies having a financial stature to seek and hire the professional advice they need to secure legal compliance, it does not seem realistic to expect that SMEs have the same means of complying with this highly complex regulation. Due to their low level of awareness and because Brazil now has a mandatory online registration system (SisGen) to monitor ABS compliance, micro and small enterprises 
are at a high risk of heavy sanctions and penalties prescribed by the regulatory decree in the case of enforcement acts by the government.

Another area of complexity is finding the "rightful" TK holder or provider community. It can be a major challenge and a moving target. Various communities may claim to be "the" TK holder, leading to protracted processes to establish the legitimacy of these claims. It can happen that a new TK holder is designated by the authorities and ABS negotiations have to start from scratch. Whilst providing some clarity on the one hand, designating TK holders for a specific resource creates the potential for a monopoly and therefore bears the danger of holding the user to ransom during negotiations. TK holders are often unaware of the national legal frameworks, posing challenges during ABS negotiations. TK holders are only slowly becoming aware of the national legal frameworks, which can lead to uneven playing fields during negotiations.

In the provider countries, regulators and TK holders alike often do not have sufficient understanding of the complexity of supply chains, cost of transactions, value creation processes, need for large amount of capital, or return on investment, etc. This can lead to over-simplistic and unrealistic demand scenarios of proposed benefit sharing. Defining what is "a fair and equitable sharing of benefits" is very problematic-especially when downstream processing does not necessarily use the TK but adds considerable value to the resource by applying new processes, involving substantial capital and intellectual property of the processor, and the cost to achieve market access, etc.

The utilisation of transboundary resources, e.g., Marula or Devils Claw in Southern Africa (e.g., [12]), poses additional challenges; traders may access plant material in a country with no or straightforward ABS obligations and sell to countries with more demanding ABS laws where the same plant is also native, thereby gaining a competitive edge by circumventing ABS obligations.

Often, the initial local regulations prove to be impractical, go through a series of adaptations as well as evolving interpretations on the actual execution, or a combination thereof. Finally, timelines for achieving PIC, benefit sharing agreements, and local permits for access tend to be very long, which, in a fast-moving consumer-oriented world, creates real disincentives for utilization of genetic resources. A case in point is the high-profile rooibos benefit sharing agreement that required nine years of negotiations [13], but also most of the PIC and benefit sharing agreements elsewhere took more than 2 years to reach delivery of the corresponding ABS permit [14].

\subsection{Material Scope of the Nagoya Protocol and of ABS Legislation}

As introduced above, the Nagoya Protocol sets minimal standards, but national ABS laws can be more or less encompassing. In the formal scope of the CBD and the Nagoya Protocol are "genetic resources", defined as "genetic material of actual or potential value" [1]. "Genetic material", in turn, is defined as "any material of plant, animal, microbial or other origin containing functional units of heredity". These definitions make it quite clear that only tangible biological materials are in the intended scope of the CBD and the Nagoya Protocol. Still, due to rapid advances in DNA sequencing and in digital technologies, claims have been made that, in the spirit of the main objectives of the CBD, also (intangible) information related to genetic resources (such as DNA sequence data stored in public, open-access databases) should be understood to be included in the formal scope of ABS obligations under the Nagoya Protocol. This is argued as being necessary to encompass an increasing portion of biotechnology products that would otherwise "escape" ABS obligations (e.g., [15,16]).

An increasing number of countries are deviating from the material scope of the Nagoya Protocol in their national implementation. For instance, the Brazilian ABS legislation deals with "genetic heritage" rather than "genetic resources", where genetic heritage is defined as genetic information from plants, animals, and microbial species, or any other species, including substances originating from the metabolism of these living organisms. Moreover, in other countries, "digital sequence information" is included in the formal scope of ABS 
obligations, for instance in Bolivia, Brazil, India, or Kenya [17], and the issue is still a matter of debate in the state of Queensland in Australia [8]. In addition, although some countries only regulate access to genetic resources that are native in their territory, others-such as India-also include genetic resources that have been introduced deliberately in their territory in the scope of their ABS legislation; in other words, an imported plant variety falls in the potential scope of the Indian ABS legislation as soon as it is grown for the first time on an Indian field. If that plant is subject to ABS obligations from its country of origin, this may mean a double burden for commercial users, both in terms of benefit sharing and ABS compliance procedures to be followed.

In mainland France, the original ambition was to establish a specialized ABS scheme for cultivated plants and domesticated animals. However, in 2017, the Ministry of Agriculture dropped this plan. As a consequence, no ABS obligations apply to such genetic resources. Still, in practice, the distinction between "wild" and "cultivated" plants, or between "wild" and "domesticated" animals is blurry and under clarification with the environmental authorities. The practical definition of "derivatives", which are outside the material scope of the ABS legislation of mainland France, is also still under discussion between potential users (i.e., industry and academia) and the French National Competent Authority.

\subsection{Temporal Scope of the Nagoya Protocol and of ABS Legislation}

The CBD and the Nagoya Protocol require prior informed consent (PIC) from the country of origin (or a provider country that has acquired the genetic resource from the country of origin in accordance with the CBD) before accessing the genetic resource. Therefore, ABS obligations should only apply to genetic resources accessed directly from a provider country after entry into force of its national ABS laws. In line with one of the basic principles of international law, i.e., the principle of non-retroactive application, it is essential for legal certainty that there are no retroactive ABS obligations, because users can only strive for compliance with legal requirements if they know the specific ABS obligations in advance of starting a new project. A further complicating factor is that for many genetic resources accessed in the past, the origin may no longer be known. In addition, due to the global nature of trade and R\&D collaborations, trajectories of genetic resources over time may be complex and difficult or impossible to trace. Finally, current genetic resources may have ancestors from many different countries. All in all, trying to expand the principles of the Nagoya Protocol to genetic resources accessed in the past (i.e., before entry into force of relevant ABS legislation) would not only be contrary to basic principles of international law (article 28 of the 1969 Vienna Convention on the Law of Treaties [18]), but would also not match with the practical realities of R\&D.

Still, some countries have chosen to claim retroactive ABS obligations, in two distinct ways. For example, South Africa also applies its ABS legislation to established commercial uses of its genetic resources (i.e., for commercial products and processes developed and established before entry into force of its ABS legislation), because all utilization of indigenous biological resources needs to go through a permitting application-independently of whether there is indigenous knowledge involved or not. An example for such retroactive application is the rooibos benefit sharing agreement concluded in 2019 between the indigenous San and Khoi peoples, the South African government, and the rooibos industry (notably after a 9-year negotiation process as mentioned earlier [13]). A different approach was chosen by, e.g., France where "new utilization" rather than "access" is triggering ABS obligations. This means that a user who acquired a French genetic resource in full compliance with all applicable laws before entry into force of the French ABS legislation is still expected to apply for an ABS permit if they attempt to explore a "new utilization" for that particular genetic resource. Discovering that a plant previously used only in food contains components with interesting effects on hair growth would likely represent a "new utilization". On the other hand, R\&D leading to incremental improvements of a product in its established applications might not qualify as a "new utilization". However, there 
is a continuum between these two extremes, and it seems unclear where to draw the line between a "new" and an "old" utilization. This, in turn, creates legal uncertainty.

\subsection{The Importance of Timing of Benefit Sharing Negotiations along the Innovation Trajectory}

The Nagoya Protocol stipulates that a provider country may require an ABS agreement (i.e., receiving PIC and negotiating mutually agreed terms (MAT)) from a prospective user before access and before the start of "utilization" of a genetic resource (understood as performing research and development on the genetic or biochemical composition of a genetic resource, or both). At such an early point in time, it is often impossible or at least very difficult to estimate the commercial value of a potential innovation. Accordingly, provider countries might attempt to (i) initially agree on benefit sharing terms for the R\&D phase only, and (ii) ask users to return at the end of development to agree on benefit sharing obligations for commercial use. Brazil, on the other hand, has chosen not to impose benefit sharing obligations during the R\&D phase, nor for the commercialization of intermediate products along the production chain, nor for micro and small businesses. However, an R\&D registration is required before transferring a sample abroad. Then, the product notification is realised by users on the online registration system (SisGen) prior to economic exploitation of a finished product or reproductive material, originating from access to genetic heritage or to associated traditional knowledge (TK). During the notification step, users must declare compliance with the law and must indicate the modality of benefit-sharing (monetary or non-monetary), when applicable, to be established in the benefit-sharing agreement. Monetary benefit sharing should represent $1 \%$ of the annual net revenue obtained from economic exploitation of finished products or reproductive material, i.e., financial benefits are shared per fiscal year after product commercialization. If non-monetary benefit sharing is chosen by the user, it shall be negotiated in a fair and equitable way between users and genetic heritage or TK providers and provided according to contractual agreements.

Another example is France, where access to a genetic resource for R\&D needs to be notified to the authorities and where later, in case of potential entry into the market, an authorization process - referring to the benefit sharing agreement for commercializationneeds to be followed.

The crucial question for users is whether (i) to negotiate PIC and MAT covering only the R\&D phase and then to re-start the negotiation from scratch when approaching commercialization; or (ii) to conclude a benefit sharing agreement including commercial terms already in an early R\&D phase when it is hardly possible to predict commercial feasibility and potential. As outlined above, only a limited percentage of R\&D projects reach the commercial stage, and multiple hurdles and risks need to be overcome, sometimes over a prolonged period of time, to turn an idea into a commercially viable innovation. Therefore, investors have a vital interest in reducing the risks, and know in advance the potential obligations. Spending significant time and financial resources for R\&D without certain knowledge of whether the benefit sharing negotiations for commercial use will at all be successful or may still allow a viable business case is not an attractive prospect for investors and innovators. A benefit sharing cap of $1 \%$ of annual net revenue-as foreseen under the Brazilian ABS legislation-might already ruin a business case for some products with low profit margins derived from a single genetic resource, but rapidly become a serious issue in the case of cumulative benefit sharing obligations for products derived from multiple genetic resources (see below). Such uncertainty or constraints are detrimental to companies and to local communities, as benefits are not shared as they could be. In addition, this may cause some users to escape to provider countries with no, or more proportionate, ABS obligations; this, however, risks compromising the ambitions of the CBD. The effectiveness of the Nagoya Protocol and of national ABS legislation can only be guaranteed if clarity, replicability, and easy to navigate rules are provided. 


\subsection{A Simple Use Case May Still Lead to Stacking of Obligations}

Discussions on ABS are often dominated by a simplistic theory that for a given innovation, one genetic resource is accessed, that only one ABS agreement will be required, and that benefit sharing will only need to be performed with one provider country. According to this view, a pharma company would access a plant from the Amazon rainforest, would develop a new blockbuster drug, and would share the benefits fairly and equitably with, e.g., Peru. Or a cosmetic company would access another plant in Vietnam, develop a new essential oil, and use the origin of the plant in its marketing efforts. Examples of several such $\mathrm{ABS}$ agreements have been published, covering the medical, cosmetic, and personal care sectors [14].

Allow us to have a closer look at a concrete example. When producing a consumer product, a personal care company will typically blend multiple ingredients obtained from different suppliers. The individual ingredients may be obtained from biological resources, or may be produced chemically or by biotechnological processes. For each ingredient, the personal care company will need to analyse the ABS legislation of a given provider country, and possibly judge whether "utilization" was involved in the development of these products, whether bio-trade (without "utilization") is in the scope of benefit sharing obligations, or both [19].

Figure 2 shows the composition of a typical commercial hair conditioner. What if the argan oil was from Morocco? What if the Aloe barbadensis leaf juice was from Saudi-Arabia, India, or Mexico? What if the coconut oil was from the Philippines, Malaysia, or Indonesia, or from several countries? What if the avocado oil was from Mexico, South Africa, or Colombia? What if citric acid was produced by industrial fermentation, using a fungal production strain?

\section{Composition: Water, Cetearyl Alcohol, Cetyl Alcohol, Behentrimonium Chloride, Glycerin, Dimethicone, Argania Spinosa (Argan) Kernel Oil, Cocos Nucifera (Coconut) Oil, Persea Gratissima (Avocado) Oil, Theobroma Cacao (Cocoa) Seed Butter, Aloe \\ Barbadensis Leaf Juice, Hydrolyzed Keratin, Panthenol, Cyclotetrasiloxane, Glycol Distearate, Glycol Stearate, Cyclopentasiloxane, Ceteareth-20, Isopropyl Alcohol, Citric Acid, Tetrasodium EDTA, DMDM Hydantoin, Phenoxyethanol, Fragrance, Benzyl Salicylate, D-Limonene, Hexyl Cinnamal, Butylphenyl Methylpropional, Linalool, Cl 16035/Red 40, Cl 19140/Yellow 5.}

Figure 2. Composition list of a typical commercial product from the personal care industry.

The hair conditioner example illustrates a possible case of six different potential ABS obligations to be met by users for a single product. In the case of stacking of ABS obligations, the question arises of how to determine the relative value of each component or input into the development of the eventual commercial product. In addition, more importantly: how to negotiate with multiple provider countries about a fair share of the benefits generated with a particular product that is subject to multiple benefit sharing obligations?

Even if the stacking of obligations may not yet appear to be a major issue, it seems important to stress two points: first, the implementation of the Nagoya Protocol at the national level is still in the ramp-up phase, with countries implementing new ABS laws and starting to address the backlog of concluding ABS agreements for what they consider to be in scope of their ABS regulations. In addition, most of the products currently on the market or the starting materials for those which are currently under development predate entry into force of the national ABS laws and should therefore not be subject to ABS regulations. However, this will rapidly change over time, due to the very nature of the Nagoya Protocol, which does not foresee any cut-off points in terms of material or temporal scope of obligations, leading to eternal and cumulative ABS obligations. Second, even if only an individual component of (or input for) a product was subject to ABS obligations, it 
is a very demanding task for companies to apply the required due diligence to confirm and conclude that all the other components (or inputs) are not subject to any ABS obligations.

\subsection{Dealing with the Complexity of Commercial Value Chains}

It is currently very rare that a single individual or company accesses a genetic resource, generates a value-added product, and sells it directly to the final customer. Instead, typical commercial value chains are complex, intertwined, and often long, meaning that multiple companies along the value chain contribute separate steps to the design of the final product. Figure 3 is a simplified schematic representation of one such value chain, and serves to highlight several of the potential complexities involved: (i) at each step of the value chain, R\&D on genetic resources may be involved, potentially triggering cumulative ABS obligations; (ii) at each step of the value chain, the product may either be the final product in itself (e.g., milk), or may serve as a starting material for a different field of use; and (iii) at each step of the value chain, a product may go into different end markets, with different value propositions.

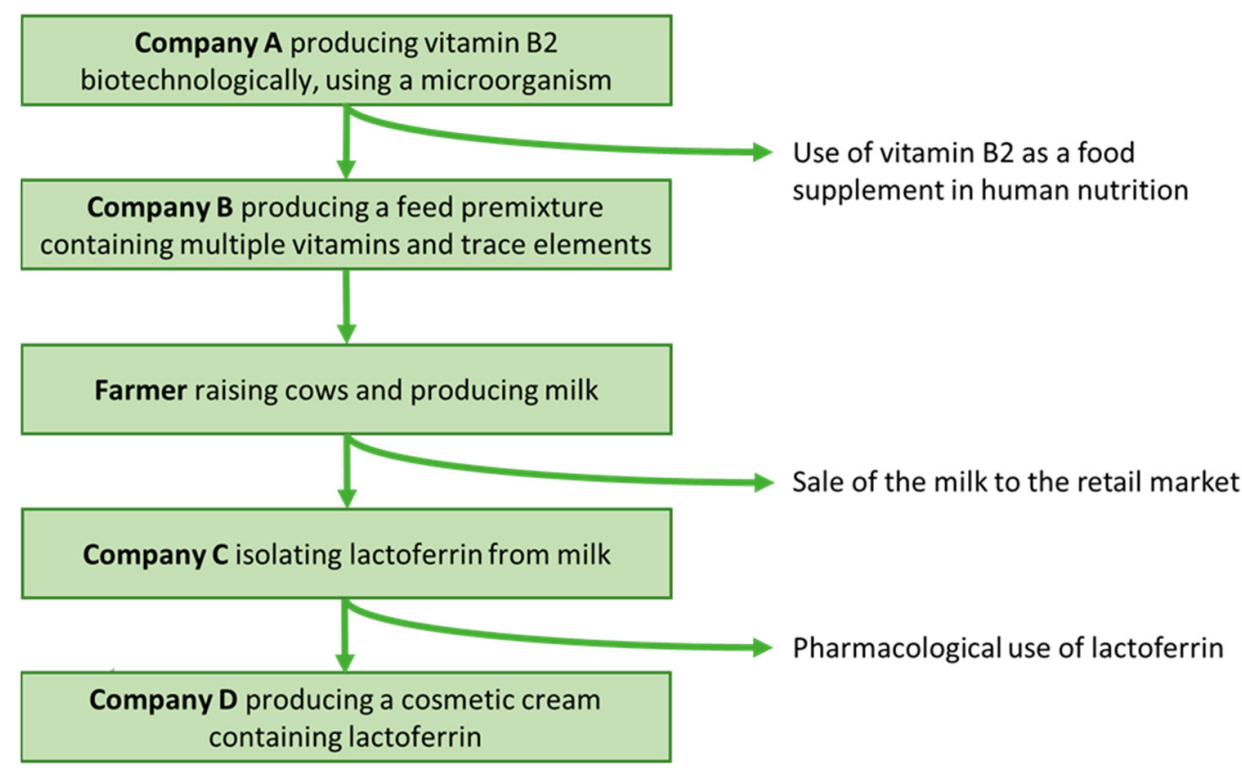

Figure 3. Schematic representation of a typical value chain.

Consequently, the pertinent questions are: At which stage of the value chain should benefit sharing be performed? At an individual, clearly defined step, or at multiple steps along the value chain? If the answer is all along the value chain, how should the fair share that each party should contribute to the overall benefit sharing scheme be defined? Unfortunately, there is currently no harmonized global understanding of how to address and resolve this issue. It may be argued that the added value of the microorganism used for vitamin B2 production by Company A in Figure 3 is restricted to that particular step, and that - if the microorganism were subject to ABS obligations-only Company A would need to comply with such obligations, but not all users further down in the value chain. However, some countries have expressed that they expect benefit sharing to be performed at the very end of the value chain, as at that stage, there is the most value to share. This would result, however, in many of the complexities mentioned before: it would require a lot of bureaucratic paperwork back and forth along the value chain to keep each other informed on obligations and final uses, and in fulfilling the requirement of applying due diligence in defining whether all the applicable benefit sharing obligations are properly respected; and it would result in the stacking of ABS obligations and in difficulties in defining what each individual component (or input) contributes to the final value of the end product. 


\subsection{The Complexity of Plant Breeding}

Plant breeding is a complex use case. A simple core workflow of the R\&D process (see Figure 4) requires access to multiple genetic resources, from multiple countries, which are then intermingled (often over several or multiple breeding cycles). The commercial material obtained may again be used as a starting point for a new breeding campaign.

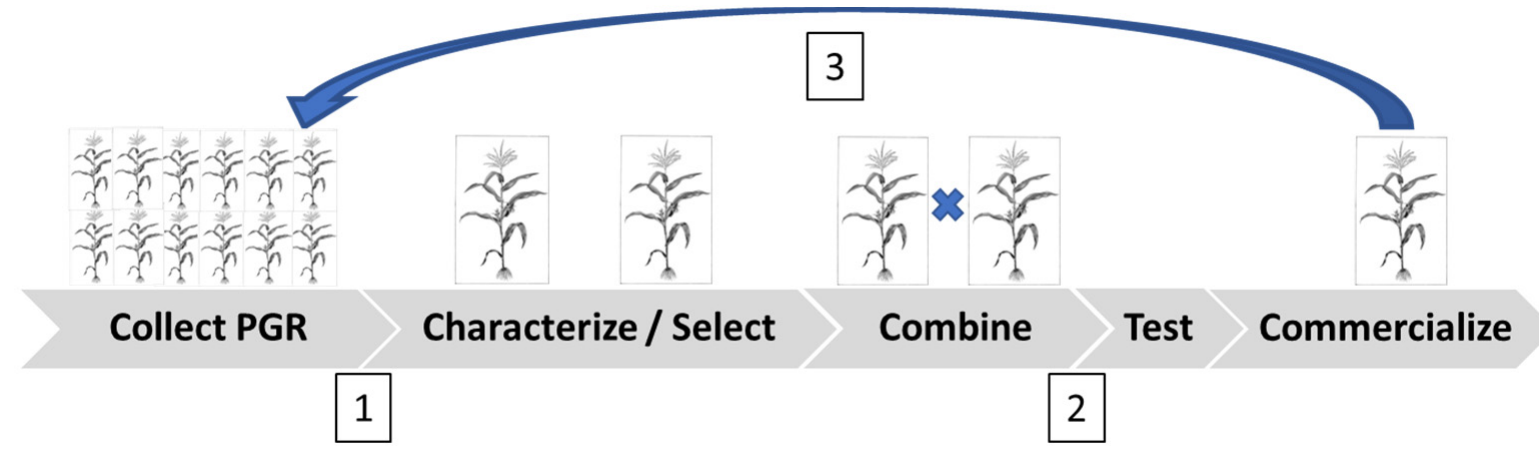

Figure 4. Core workflow in plant breeding: (1) Plant breeders need a collection of genetically diverse breeding materials (plant genetic resources and PGR) to characterize and select suitable materials for the breeding of new varieties. (2) Breeders make crosses, and then in populations of plants with segregating traits, they select plants with desired characteristics, and remove undesired ones. The process eventually allows to create improved varieties that are worth commercializing. (3) Breeders purchase each other's commercial seed and use it for the next breeding cycle. This is a very common practice and is a cornerstone for making incrementally better varieties, thereby contributing to food security. The time from characterization to commercialization is 5-10 years or longer, depending on the crop and the breeding objectives.

Plant breeding delivers thousands of new varieties each year [20]. Because of the large number of varieties in development at any given time, focusing on a single variety could be seen as anecdotal, and it is thus more suitable to discuss the overall process.

Operating the core workflow in the current environment of ABS laws creates a variety of challenges: a new breeding program needs lots of genetic diversity as starting material. Some of this diversity must be accessed from specific countries: centres of origin, centres of diversity, or countries where desired traits can be found. Moreover, for existing programs, new breeding objectives (e.g., pest and disease resistance, and adaptation to climate change) often require access and screening and tenuous characterization of new starting materials, so that new access is a continuous requirement. Screening programs for desirable traits require access to lots of plant genetic resources, of which only a few will be used in generating the final, new commercial variety. However, even for a single plant genetic resource, it is often not easy to produce PIC and MAT via bilateral agreements (for examples, see [4]). For a new breeding program, ABS requirements are a major challenge to establish a relevant collection of starting materials, and ABS laws create an entry barrier.

Most plant varieties used in breeding crosses are varieties that are already cultivated and have been collected, transferred, combined, sold, and traded internationally for a long time, and thus have ancestors from different countries, as shown schematically in the pedigree in Figure 5. As a real-life example, the pedigree of the Khumal-4 rice variety has been presented by MoAD [21].

In fact, in a plant variety, each gene, or group of genes, can be claimed as a genetic resource, with its own provider. What if a variety is accessed with PIC and MAT from country A, and later-on countries B, C, D and E also claim to be countries of origin of ancestors which have been used previously in the breeding of the variety accessed from country A? Even material from public germplasm collections can trigger unexpected claims from certain provider countries, as happened when the Indian National Biodiversity Authority claimed sovereign rights for a melon variety that had left India long before it 
had a biodiversity act in place [22]. For plant breeding and for other purposes, the rules for access and use of cultivated plant varieties is very different in each source country.

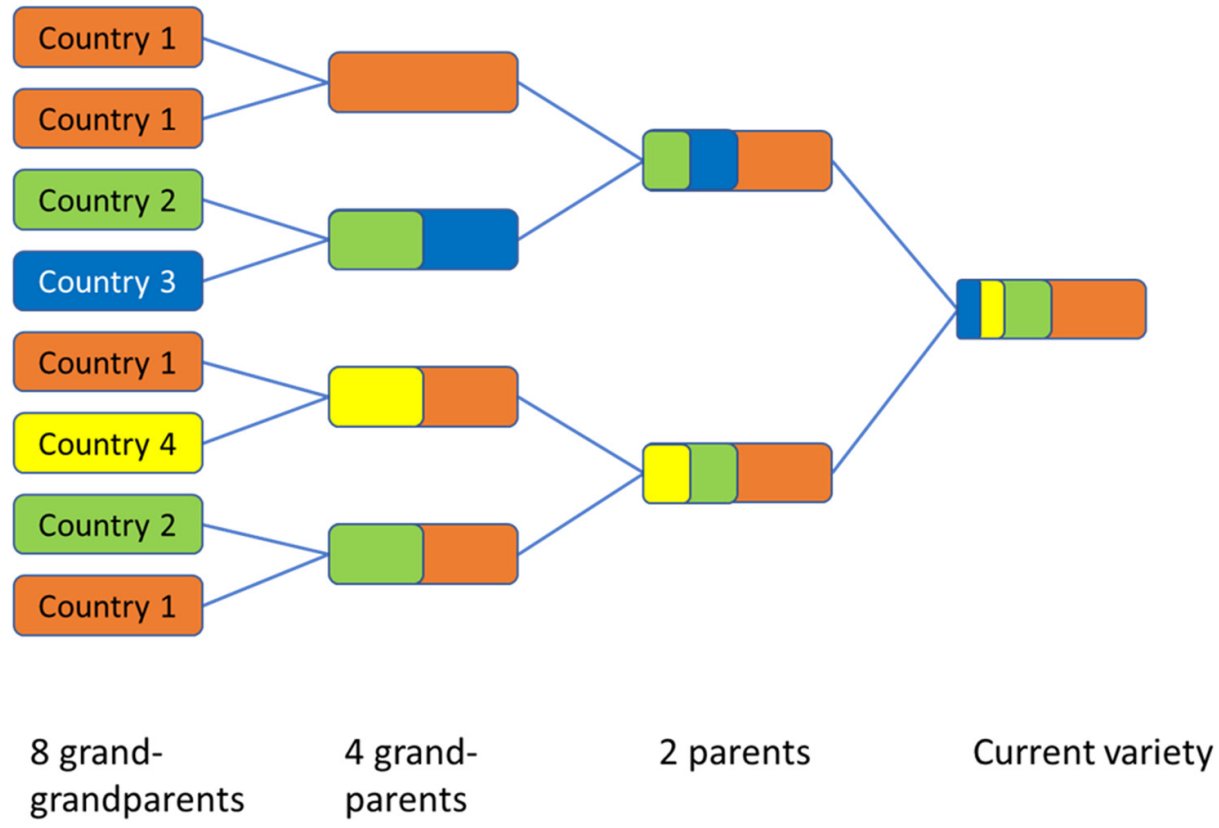

Figure 5. A cultivated plant variety often has a pedigree that refers to multiple countries of origin. The areas of the different colours indicate how much "heritage" from the initial starting countries is still present in any given progeny. The case may still seem rather simple after three generations of mating, but becomes rapidly much more complex with increasing numbers of generations.

Every cross stacks the contractual ABS requirements of its parental lines. Even though breeders are used to working with materials subject to legal obligations, third party rights, or both, ABS adds a dimension of unprecedented complexity. Moreover, many of the ABS agreements are not adapted to 'stacking in a breeding program'. Other third party rights usually expire at some point, whereas ABS obligations are often perpetual.

Some countries' ABS laws specify that use of commercial seeds for new R\&D is subject to $\mathrm{ABS}$ requirements. However, when buying commercial seeds, it is usually not possible to know the underlying ABS requirements, let alone to comply with them. Commercial seed that is purchased for use in further breeding may have parents or material higher up in the pedigree from a country such as India, that requires ABS permits for use of its genetic resources, possibly with retroactive effect, even if purchased as a commodity in a country that does not impose ABS obligations for its own genetic resources. It seems that ABS laws of one country can create legal uncertainty at a global level, in a core workflow supporting food security.

Making a cross is a major decision, also because once a plant breeder has 'utilized' a genetic resource in a cross, it is part of the genotype of all progenies, and it is not possible to 'change supplier'. If there is a request to stop utilization, because of new ABS laws or different interpretations of their scope, this implies discarding all breeding materials that used the genetic resource.

ABS also affects characterization of newly accessed plant genetic resources and of the progeny of crosses. For some traits, this requires trials in multiple countries, and biochemical and genetic analysis. Selecting, characterizing, and testing plant varieties for their disease resistance requires access to pathogens from diverse origins, and some countries require $A B S$ permits for use of pathogens. Breeders use genetic sequence information in mapping, genetic prediction, characterization, and diagnostics. Characterization and selection of breeding material also has specific time constraints: if an ABS permit comes 
one week too late, the planting season will be missed, which may result in a delay of a full year.

Commercial varieties may contain traits or genetic elements that were developed by others in pre-commercial research (see [23] for an illustrative case in oilseed rape), and this can create a lot of value for multiple stakeholders. Pre-commercial R\&D in the public sector is often brought to commercial products via cooperation agreements with the private sector. This implies the need to hand over material and ABS information to 'subsequent users'. For plant varieties, however, it is difficult to validate that this information is complete, especially because materials may depend on several access agreements, and even single ABS laws may be difficult to assess. It is difficult for a legal department of the provider and the recipient to confirm ABS compliance.

A real-life plant breeding program produces a few varieties per year per crop, and therefore has multiple workflows (breeding cycles) running in parallel, often in different countries, and exchanges material between countries. Overall, ABS creates complexity at several points in the core breeding workflow and the combination of the above issues has more than an additive effect.

Awareness about the particular problems for plant breeding mentioned above, on top of the generic problems of legal complexity, material scope, temporal scope, and stacking of obligations, led to the adoption in 2001 of a special instrument to address them, the Multilateral System (MLS) of the International Treaty for Plant Genetic Resources for Food and Agriculture (ITPGRFA, [24]). It enables major simplifications by a standard access agreement, the need for royalty payments only at commercialization, and a standard royalty rate that is not cumulative. Seed associations have stated that the MLS is for them a preferred ABS mechanism. However, the scope of the MLS is incomplete: it does not cover all crops (e.g., cotton, soybean, and most vegetable species are not covered), and it only applies if the crops are used for food and agriculture. Even for the 64 crops that are in scope of the MLS (the so-called annex-1 crops), not all countries contribute all relevant materials, and a survey indicates that when materials are requested that are in the MLS, about half of the requests do not lead to seed delivery [25]. In 2019, there was an initiative to ensure monetary income without lag time, and to make the MLS more business-friendly and to expand its scope, so that it would include all crops for food and agriculture. Unfortunately, this initiative received insufficient support from the ITPGRFA contracting parties. As a consequence, some plant genetic resources are available via the MLS, while others fall under the national ABS laws.

Mekonnen and Spielman [26] have analysed germplasm exchange and found that a country becoming a member of the CBD is closely associated with a reduction in the actual sharing of its genetic resources, while ITPGRFA membership has an opposite association. Based on these insights, these authors suggest that also the Nagoya Protocol will likely affect global flows of plant genetic resources for food and agriculture (PGRFA) in a negative and unintended manner.

Overall, plant breeders operate in a very complex R\&D process and value chain. Plant breeding can deliver multiple socio-economic and environmental benefits [27]. We-as private sector representatives-fear that superimposing a very complex ABS environment may lead to lost opportunities in food security, managing the ecological footprint of agriculture, and in biodiversity conservation [28]. ABS may also create an entry barrier for new plant breeding programs. Breeding programs for smaller and less profitable crops may most likely no longer be worthwhile, so they will suffer most. In that sense, ABS mechanisms hinder progress towards CBD objectives and also several of the United Nations' Sustainable Development Goals.

The full effect of ABS on the breeding output may not yet be visible. Varieties coming to market now are based on crosses made several years ago, and on plant genetic resources accessed often before ABS laws existed. When the effect of ABS laws on breeding output becomes visible, it may be strongest for market segments with less profits, and for crops where access is more difficult. 


\section{Conclusions}

We hope that we have managed to sketch the challenges encountered by the private sector due to the sheer complexity created by up to 200 different national ABS frameworks (as well as further differences at provincial or local levels) and the complications created by the non-linear realities of product development, commercial value chains, and the non-harmonized implementation of the Nagoya Protocol. These factors make it extremely challenging for companies to follow the legislative developments and, even more so, to secure compliance with all applicable ABS laws. Companies often use hundreds or even thousands of raw materials that represent, or may be derived from, genetic resources, either for R\&D or commercial production. For each raw material, it is common practice to have several suppliers with different levels of understanding of relevant ABS provisions, and the choice of suppliers will also change over time.

Applying due diligence in figuring out whether or not ABS obligations apply binds significant human resources all along the value chain. We would like to emphasize that our companies, but also many if not most of our peers, spend significant efforts in securing ABS compliance, in terms of: education and alignment (internally, with peers and other stakeholders, and along the value chains); monitoring and assessing the evolution of the regulatory landscape; defining and implementing best practices; concluding ABS agreements or qualifying suppliers; and contributing to the international discussions on the experiences with and the future of ABS). In our experience, the efforts we need to spend on compliance issues are disproportionate to the benefits which are or could be generated and shared through ABS agreements.

The complexities outlined have another important implication. As indicated, investors have a vital interest in reducing risks, and it is fair to say that the field of ABS still offers significant risk potential. In addition, even if a company applies best efforts in securing ABS compliance, it still runs a considerable risk of missing out on new legislative developments, misinterpreting legislation, or lacking the relevant inputs from its suppliers. Taken together, this creates a strong incentive to stay away from the current ABS jumble and thereby to protect the company's reputation, rather than to embark on a risky ABS journey, trying to comply, but suddenly being exposed, despite best efforts, to an ABS non-compliance case.

All in all, and in line with other authors (e.g., [29-32]), we believe that the entire approach to the fair and equitable sharing of benefits for the conservation and sustainable use of biodiversity needs to be fundamentally reviewed and revised. Such revision should resolve the complexities and constraints mentioned in this paper, and reconcile the needs of users with realistic expectations of provider countries. Simpler benefit sharing mechanisms, faster issuance of relevant permits and lower transaction costs will all contribute to unlocking commercial potential faster and leading to increased use of both genetic resources and TK for the benefit of all stakeholders. Furthermore, we need workable ABS mechanisms before we discuss policy options, such as the sharing of benefits arising from the use of "Digital Sequence Information" [33].

Questions that may be worthwhile asking in the quest for a new approach to ABS are: How is ABS currently contributing to the realization of the objectives set out in the CBD and the Sustainable Development Goals? To what extent have national ABS systems delivered benefit sharing thus far? And to what extent has ABS contributed to support biodiversity conservation until now? Transparent sharing of such experiences and data at national level will provide valuable insights for the design of a revised approach to a more efficient ABS system which delivers on its objectives. This could be an interesting work in view of the upcoming adoption of the Post-2020 Global Biodiversity Framework at the upcoming 15th meeting of the Conference of the Parties to the CBD (COP15). The private sector looks forward to contributing its perspective to this high-ambition framework.

Author Contributions: All authors contributed to the conceptualization, writing, reviewing and editing of the article. All authors have read and agreed to the published version of the manuscript.

Funding: This research received no external funding. 
Institutional Review Board Statement: Not applicable.

Informed Consent Statement: Not applicable.

Data Availability Statement: Not applicable.

Acknowledgments: Felicity Keiper, Dominic Muyldermans, Daphne Yong d'Hervé and Swati Gupte are gratefully acknowledged for stimulating discussions and for critically reviewing draft versions of this paper.

Conflicts of Interest: The views and opinions expressed in this article are those of the authors in their personal capacity. None of the observations, opinions, or conclusions expressed herein are to be attributed to or construed as the views or positions of any organization, association or company.

\section{References}

1. United Nations. Convention on Biological Diversity. 1992. Available online: https://www.cbd.int/convention/text/ (accessed on 19 November 2021).

2. United Nations. Nagoya Protocol on Access to Genetic Resources and the Fair and Equitable Sharing of Benefits Arising from Their Utilization to the Convention on Biological Diversity. 2011. Available online: https://www.cbd.int/abs/doc/protocol/ nagoya-protocol-en.pdf (accessed on 19 November 2021).

3. International Chamber of Commerce. Encouraging ABS Agreements and Sustainable Use of Genetic Resources. 2018. Available online: https:/ / iccwbo.org/publication/encouraging-abs-agreements-sustainable-use-genetic-resources/ (accessed on 19 November 2021).

4. Milieu. Analysis of Implications of Compliance with the EU ABS Regulation for Research Organisations and Private Sector Companies. 2020. Available online: https:/ / ec.europa.eu/environment/nature/biodiversity/international/abs/pdf/ABS\%20 Regulation_Report\%20on\%20Compliance\%20Implications\%20for\%20public\%20and\%20private\%20sectors.pdf (accessed on 19 November 2021).

5. Convention on Biological Diversity. First Draft of the Post-2020 Global Biodiversity Framework. Document No. CBD/WG2020/3/3. 2021. Available online: https:/ / www.cbd.int/doc/c/abb5/591f/2e46096d3f0330b08ce87a45/wg2020-03-03-en.pdf (accessed on 19 November 2021).

6. Deutz, A.; Heal, G.M.; Niu, R.; Swanson, E.; Townshend, T.; Zhu, L.; Delmar, A.; Meghji, A.; Sethi, S.A.; Tobin-de la Puente, J. Financing Nature: Closing the Global Biodiversity Financing Gap. The Paulson Institute, The Nature Conservancy, and the Cornell Atkinson Center for Sustainability. 2020. Available online: https:/ /www.paulsoninstitute.org/wp-content/uploads/20 20/10/FINANCING-NATURE_Full-Report_Final-with-endorsements_101420.pdf (accessed on 19 November 2021).

7. David, B.; Wolfender, J.-L.; Dias, D.A. The pharmaceutical industry and natural products: Historical status and new trends. Phytochem. Rev. 2015, 14, 299-315. [CrossRef]

8. Lawson, C.; Humphries, F.; Rourke, M. Legislative, Administrative and Policy Approaches to Access and Benefit Sharing (ABS) Genetic Resources: Digital Sequence Information (DSI) in New Zealand and Australian ABS Laws. Intellectual Property Forum, Issue 118. 2019. Available online: http:/ / hdl.handle.net/10072/394991 (accessed on 19 November 2021).

9. UNDP-GEF. Strengthening Human Resources, Legal Frameworks, and Institutional Capacities to Implement the Nagoya Protocol (Global ABS Project). 2021. Available online: http:/ / nbaindia.org/uploaded/pdf/IDB_ABS.pdf (accessed on 19 November 2021).

10. Brazilian Ministry of Economy. Governo Destaca Papel da Micro e Pequena Empresa Para a Economia do País. 2020. Available online: https:/ / www.gov.br/economia/pt-br/assuntos/noticias/2020/outubro/governo-destaca-papel-da-micro-e-pequenaempresa-para-a-economia-do-pais (accessed on 19 November 2021).

11. Brazilian Law 13.123/2015. Available online: https:/ / absch.cbd.int/database/record/ABSCH-MSR-BR-238963 (accessed on 19 November 2021).

12. El Mohamadi, A. Report on the First Regional Workshop on a Marula Sector Development Plan, Windhoek, 4 \& 5 November 2019. Available online: https:/ / unctad.org/system/files/official-document/ditc-ted-05052020-BioTradeSSC-Marula-report.pdf (accessed on 19 November 2021).

13. Schroeder, D.; Chennells, R.; Louw, C.; Snyders, L.; Hodges, T. The rooibos benefit sharing agreement-Breaking new ground with respect, honesty, fairness, and care. Camb. Q Healthc. Ethics 2020, 29, 285-301. [CrossRef]

14. Normand, V.; Oliva, M.J.; Müller, S.; al-Janabi, S.; Zohren, Y.; Nöske, N.; Zedda, L.; Paulsch, A. The Contribution of Access and Benefit-Sharing (ABS) to the Sustainable Development Goals. 2021. Available online: https://absch.cbd.int/database/VLR/ ABSCH-VLR-SCBD-253097 (accessed on 19 November 2021).

15. Aubry, S.; Frison, C.; Medaglia, J.C.; Frison, E.; Jaspars, M.; Rabone, M.; Sirakaya, A.; Saxena, D.; van Zimmeren, E. Bringing access and benefit sharing into the digital age. Plants People Planet 2022, 4, 5-12. [CrossRef]

16. Sherman, B.; Henry, R.J. Access to biodiversity for food production: Reconciling open access digital sequence information with access and benefit sharing. Mol. Plant 2021, 14, 701-704. [CrossRef] [PubMed]

17. Bagley, M.; Karger, E.; Muller, M.R.; Perron-Welch, F.; Thambisetty, S. Fact-Finding Study on How Domestic Measures Address Benefit-Sharing Arising from Commercial and Non-Commercial Use of Digital Sequence Information on Genetic Resources and Address the Use of Digital Sequence Information on Genetic Resources for Research and Development. 2020. Avail- 
able online: https:/ / www.cbd.int/doc/c/428d/017b/1b0c60b47af50c81a1a34d52/dsi-ahteg-2020-01-05-en.pdf (accessed on 19 November 2021).

18. United Nations. Vienna Convention on the Law of Treaties. 1969. Available online: https://legal.un.org/ilc/texts/instruments/ english/conventions/1_1_1969.pdf (accessed on 19 November 2021).

19. IFRA-IOFI Guidance Document for the Flavor and Fragrance Industry for Dealing with the Nagoya Protocol and Access and Benefit Sharing (ABS) Regulations. 2020. Available online: https://ifrafragrance.org/docs/default-source/guidelines/nagoyaprotocol-guidance/il1090-09-04-2020-ifra-iofi-guidance-document-on-nagoya-protocol-and-abs-regulations(att-01)-guidancedocument-(april-9-2020).pdf?sfvrsn=5fa56977_6 (accessed on 19 November 2021).

20. UPOV. PLUTO Database. Available online: https://pluto.upov.int/ (accessed on 19 November 2021).

21. MoAD. International Treaty on Plant Genetic Resources for Food and Agriculture and Multilateral System (ITPGRFA-MLS) Implementation Strategy and Action Plan (IMISAP) 2018-2025. Ministry of Agricultural Development, Kathmandu, Nepal. 2017. Available online: https:/ / www.researchgate.net/publication/348050117_International_Treaty_on_Plant_Genetic_Resources_ for_Food_and_Agriculture_and_Multilateral_System_ITPGRFA-MLS_Implementation_Strategy_and_Action_Plan_IMISAP (accessed on 19 November 2021).

22. India. Observation Filed under Article 115 of European Patent Convention Regarding the Use of Indian Biological Resource and Non-Compliance with India's Biological Diversity Act. 2002. Available online: https://www.ip-watch.org/weblog/wp-content/ uploads/2016/01/National-Biodiversity-Authority-India.pdf (accessed on 19 November 2021).

23. Steward Redqueen. Who Benefits from Intellectual Property Rights for Agricultural Innovation? The Case of Ogura Oilseed Rape in France. 2014. Available online: https:/ / croplife.org/wp-content/uploads/2014/11/Ogura-Final-report.pdf (accessed on 19 November 2021).

24. FAO. International Treaty on Plant Genetic Resources for Food and Agriculture. Available online: https://www.fao.org/planttreaty/en/ (accessed on 19 November 2021).

25. Bjørnstad, Å.; Tekle, S.; Göransson, M. “Facilitated access” to plant genetic resources: Does it work? Genet. Resour. Crop. Evol. 2013, 60, 1959-1965. [CrossRef]

26. Mekonnen, D.; Spielman, D. Changing patterns in genebank acquisitions of crop genetic materials: An analysis of global policy drivers and potential consequences. Food Policy 2021, 105, 2-15. [CrossRef]

27. Noleppa, S.; Cartsburg, M. The Socio-Economic and Environmental Values of Plant Breeding in the EU and Selected EU Member States. An Ex-Post Evaluation and Ex-Ante Assessment Considering the "Farm to Fork" and "Biodiversity" Strategies. 2021. Available online: https://hffa-research.com/news/study-published-the-socio-economic-and-environmental-values-of-plantbreeding-in-the-eu/ (accessed on 19 November 2021).

28. Smith, S.; Nickson, T.E.; Challender, M. Germplasm exchange is critical to conservation of biodiversity and global food security. Agron. J. 2021, 113, 2969-2979. [CrossRef]

29. International Chamber of Commerce: Towards a New Implementation Strategy for Access and Benefit Sharing. Document No. 450-1123. 2020. Available online: https:/ /iccwbo.org/content/uploads/sites/3/2020/10/icc-future-implementation-of-absfor-tf.pdf (accessed on 19 November 2021).

30. Laird, S.; Wynberg, R.; Rourke, M.; Humphries, F.; Muller, M.R.; Lawson, C. Rethink the expansion of access and benefit sharing. Science 2020, 367, 1200-1202. [CrossRef] [PubMed]

31. Rourke, M.; Eccleston-Turner, M.; Phelan, A.; Gostin, L. Policy opportunities to enhance sharing for pandemic research. Science 2020, 368, 716-718. [CrossRef] [PubMed]

32. Sara, R.; Wyss, M.; Custers, R.; in 't Veld, A.; Muyldermans, D. A need for recalibration of the discussions on Access and Benefit Sharing. EMBO Rep. 2021, e53973. [CrossRef]

33. Promoting Sustainable Use and Conservation of Biodiversity through Open Exchange of Digital Sequence Information. Joint Statement by Public and Private Sector Organisations, Academic and Scientific Institutions, Data Repositories and Collections Representing a Broad Range of Stakeholders. 2019. Available online: https:/ iccwbo.org/content/uploads/sites/3/2018/06/7joint-stakeholder-statement-on-digital-sequence-information-01-08-201.pdf (accessed on 19 November 2021). 